\title{
THE KYLE WOOLLY MAMMOTH
}

Mammoths are extinct elephants of the Pleistocene epoch, or Ice Age, and early post-glacial times. The Woolly Mammoth (Mammuthus primigenius) once ranged from western Europe across Asia and North America. Many carcasses of these animals have been found in frozen soil and glaciers in Alaska and Siberia. In spite of their name they were not extremely large-a big bull standing about nine feet high at the shoulder. The tusks were long and deeply curved. The skin bore a coat of grey wool covered by long, coarse, reddish brown hair which provided protection against rain, snow, and cold, thereby allowing them to live only a few miles from the ice.

In mid-October, 1964, an estimated 20,000 persons visited a site near Kyle, Saskatchewan, where eight days were spent recovering the remains of a Woolly Mammoth. There was actually very little to be seen at the site. On top of a small, bald knoll beside a municipal road just west of
Kyle an area about 25 feet square had been roped off. Inside this enclosure a handful of men carefully and laboriously flaked dirt away from crumbling bones, pausing occasionally to apply a mixture of shellac and alcohol to the bone they had exposed to prevent disintegration. When a bone was exposed it was wrapped, along with some of the surrounding earth, in layers of burlap soaked in plaster of Paris. When the plaster had set, the bones in their wrapping were moved to a shed in Kyle; later, when the plaster hardened, they were trucked to the Museum in Regina.

Radiocarbon dating of the bones has revealed that the Woolly Mammoth remains were deposited about 12,000 years ago. This mammoth apparently died a natural death since no evidence was found of its having been killed by human hunters. Its body fell into a pond on the stagnant ice, part of a shrinking glacier which covered the area at the time, and became buried in sandy deposits of the

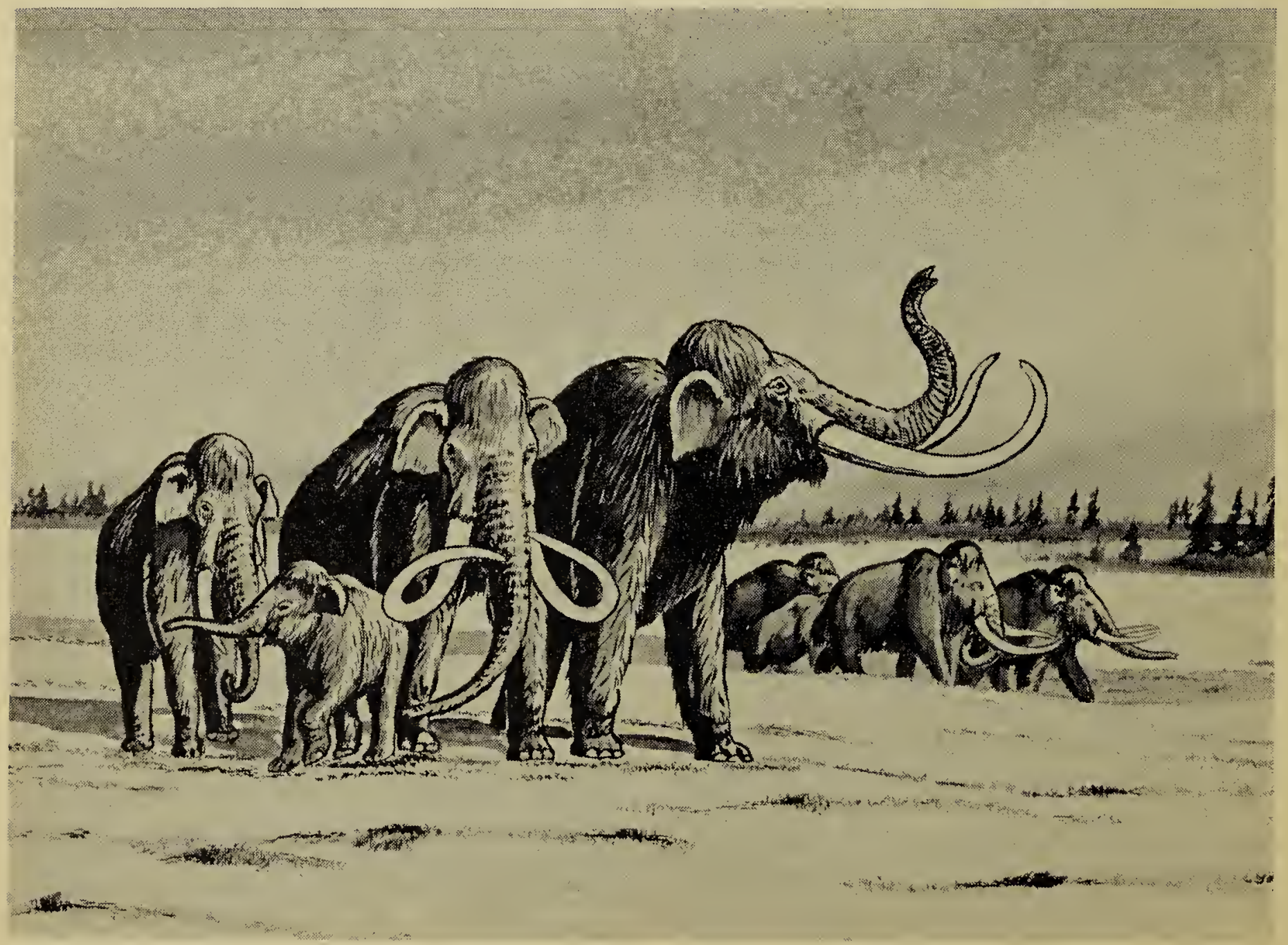


pond. With the melting of the stagnant ice, drying up of the pond occurred and the pond deposits, including the mammoth's bones, were shifted. A period of erosion followed; then, as the glaciers continued to retreat, glacial run-off produced a lake. Streams entering this lake brought with them clay in suspension and many of the mammoth's bones were the southern quarter of the province. More of the skeleton was recovered from the Kyle mammoth than from any of the previous finds. Several ribs, a femur, a shoulder blade, an upper molar tooth, an almost complete lower mandible with the massive molar in place, a tusk also nearly complete, eight vertebrae, and bones of three feet were recovered. The

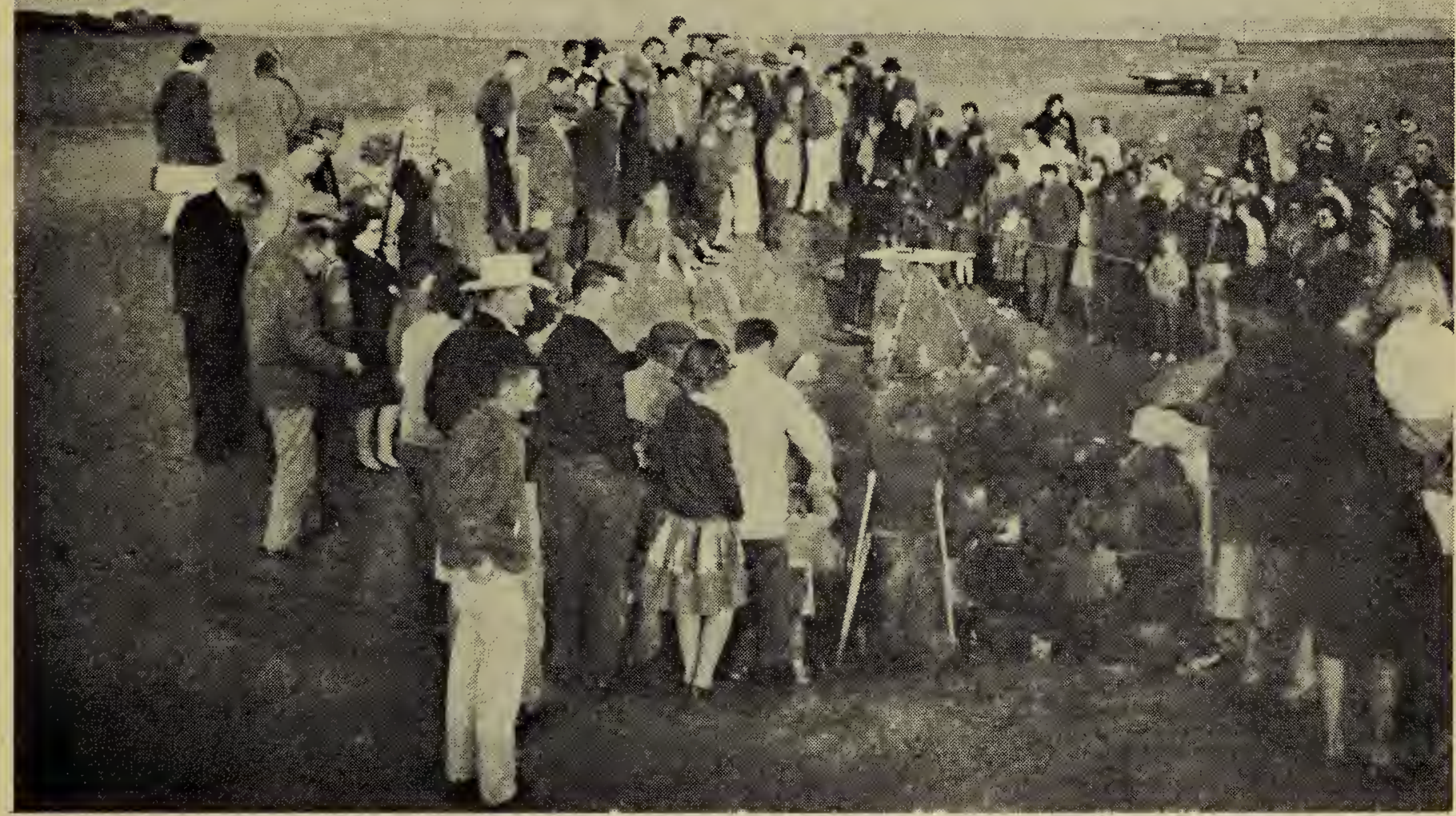

Interested public at the excavation site.

Photo by Fred W. Lahrman

covered by a protective layer of this clay as it settled to the bottom of the lake. Disappearance of the glacial lake permitted erosion to work on the landscape, but the buried mammoth was not disturbed until William McEvoy of Lacadena scraped away the covering of clay while constructing a road.

Mr. McEvoy realized the unusual nature of the bones and his prompt action in reporting them made possible the recovery by staff from the Museum, ably assisted by members of the Archaeological Society, under the direction of Thomas F. Kehoe, Curator of Archaeology at the Museum.

Remains of approximately 70 manmoths have been recovered in Saskatchewan, primarily from gravel pits in
Museum plans a display to show the bones as originally found in their matrix of earth. The bones are in an extremely delicate condition and restoration and preparation of an exhibit will take some time.

The Kyle remains are valuable principally because of the scientifically controlled excavation which enabled several pounds of bone to be removed free of contamination. The radiocarbon dating of these bones at the University of Saskatchewan in Saskatoon has provided a date for the presence of mammoths in southern Saskatchewan, and also a date muchneeded by glacial geologists for the retreat of the glacier from the area.Saskatchewan Museum of Natural History. 